\title{
Sharing systems, sharing language: designing and working in a virtual department
}

\author{
Claire McAvinia and Jane Hughes \\ Education and Professional Development, University College London \\ contact e-mail: c.mcavinia@ucl.ac.uk
}

\begin{abstract}
Less widely taught languages present special problems. Often students may be $a b$ initio learners who must progress very rapidly from beginner to highly competent. Appropriate learning materials are scarce. Small student numbers restrict the range of learner tasks. To address these problems, and drawing on research methods from both CALL and Computer Science domains, we investigated the use of a virtual learning environment (WebCT) as a tool for collaborative language teaching and learning. A web-based virtual department was created, bringing students and tutors from different institutions together to practise the target language (students) and share the development of quality resources (teachers).
\end{abstract}

The Virtual Department links three UK Danish departments. This environment provides shared working areas for students and teachers. Teachers design and use resource materials and students complete tasks. Learner task design was driven by pedagogical needs but the technology also offered opportunities which shaped the learning tasks to some extent. A key feature of the system is its range of communication tools, around which some collaborative tasks have been designed and on which students across the country can work together. The system enables teachers to create a wider variety of authentic tasks and exercises for students than previously.

The paper presents the results of evaluating the virtual department in use over one academic year with first, second and fourth year students, and their teachers.

\section{- 1. Background: difficulties for small language departments}

Universities in the United Kingdom offer students the opportunity to learn a wide range of European (including Slavonic and East European), African and Oriental languages. Many of these languages are classified by the UK funding and admissions agencies as 'minority' languages, not because of the numbers of speakers using them 
worldwide, but because of the small size of the departments teaching them, and the small numbers of teachers and students accommodated by these departments.

These small language departments face a number of pressures in their efforts to provide students with an exciting, stimulating and authentic learning experience in a less widely taught language (Roed et al, 2001). Firstly, teachers of minority languages in higher education often work in almost complete isolation. If languages such as Danish, Finnish, or Romanian are offered, it is likely that the university concerned will have only one teacher per language. Social interaction with colleagues is therefore limited or impossible, as is their assistance and support in developing course materials and new approaches to teaching. Secondly, the small number of students in class (typically between one and five) means that teachers are restricted in the variety of teaching methodologies they can adopt. The students themselves are limited by the size of their groups as they may have few fellow students with whom to practise the spoken language, or with whom they can collaborate on assignments or projects. Thirdly, the size of the market tends to dissuade publishers from producing new materials for teaching and learning these languages. Fitzpatrick (2000) highlighted the acute shortage of such materials.

New technologies, in particular web-based technologies, are often seen as means of alleviating problems of delivery which may have persisted in university courses for some time. By removing obstacles of geographical distance, as well as providing access to a much wider variety of resources, they offer the opportunity to tackle pedagogical problems in innovative ways (Warschauer, 1996). In particular, the advent of Virtual Learning Environment (VLE) tools has opened up the possibilities of integrating web-based content with communication tools, a combination that seems to promise much for language learners. Teachers, too, might benefit from a virtual environment, in which they could exchange ideas, view and comment on one another's teaching materials. This, then, was the context for the research: problem areas identified in very small foreign language departments and the emergence of technology whose use might alleviate them. Providing the technology is not the whole answer, however. Grudin (1994a) among others, shows that, for technology to be adopted in a given work situation, its design must match what users really require to do their jobs and it must be easy for them to incorporate its use into their daily work. This research aimed to find out whether a VLE and selected authoring tools could meet the needs of teachers and students in very small language departments and whether they would be able to use them in order to improve their working experience. The research took place as part of the Virtual Departments for Minority Languages (VDML) project ${ }^{1}$.

1. VDML - http://www.ucl.ac.uk/epd/herdu/vdml/ - was a two-year project, which finished in September 2002. The project was led by UCL. The other partners were the University of Edinburgh and the University of Hull. It was funded by JISC under the 5/99 DNER Programme. 


\section{- 2. Research methods}

\section{- 2.1 Overview}

An initial needs analysis was undertaken, in order to define more fully the problems experienced by teachers and students and hence to clarify the research aims. Possible solutions were explored by using a VLE tool, WebCT ${ }^{2}$, to create a prototype virtual department linking three UK university departments, and offering working areas for both students and teachers. Learning technologists and language teachers worked in partnership to create the prototype and develop online language learning materials for students to use in the virtual department. Questionnaires, interviews and focus groups were used to capture the students' subjective experience ; their activity in the virtual department was also tracked. Teachers' experiences were explored through discussions and written notes, by observing their use of the prototype virtual department and by keeping records of their requests for technical support. In order to account for some of the findings, a usability evaluation of the file management facilities of WebCT was carried out.

\section{- 2.2 Needs Analysis}

A survey (King, 2001) of approximately 60 teachers and 400 students from large and small departments was carried out by means of a questionnaire and focus groups (Lunt and Livingstone, 1996). The questionnaire aimed to establish subjects' existing levels of expertise with web-based or CALL resources, and their confidence in computer use generally. It also sought to elicit their beliefs about the role of computers in language learning and what their expectations of CALL and future materials might be. The focus groups were conducted with students of Danish and were intended to explore problem areas and students' experiences of learning in small language departments.

According to their questionnaire responses, students felt that computers could be used more in their learning. Those who were already using CALL software or other computer-based support were more likely to believe this than students with little or no such experience. Most students were web literate and used e-mail, but the majority made little use of their departments' websites and generally associated computer-assisted learning with grammar, vocabulary and written tasks rather than exercises involving spoken language or communication (King, 2001). Student focus groups reinforced the teachers' view that students had insufficient opportunities to practise spoken language, or to do group activities. The students were also aware of the lack of authentic resource materials, and sought more connection with Danish speakers and Danish as spoken in Denmark.

Teachers reported that most of the textbooks available for Danish were targeted at immigrants living in Denmark, with little material available beyond beginners' level. Audio and video resources were limited, and heavily scripted; they were reluctant to use these as they did not provide an authentic impression of spoken Danish. The teachers found that they were having to produce their own materials for use in the classroom (Roed

2 . http://www.webct.com/ 
et al, 2001) ${ }^{3}$. Finally, it was clear from both questionnaire and discussions with teachers that they were not used to developing learning materials collaboratively. It was anticipated that this was one of the human factors that would need to be addressed, since the teachers would be asked to change their working habits in order to work together in the virtual department.

The needs analysis showed that the experiences of learners and teachers in the Danish departments resembled those of many other teachers in small or 'minority' language departments: teachers working alone, a small number of students, and very few 'off-the-shelf' resources on which they could draw. This was felt to confirm that they were appropriate departments in which to pilot a virtual department and with whom to carry out the research.

The survey suggested that the focus of the pilot should be on developing both materials and opportunities for communication. The virtual department must facilitate communication between teachers, and between student groups; it should also enable teachers to build a bank of new, web-based materials to share and adapt. The research would investigate how well the technology would support these needs.

\subsection{Teacher-technologist partnership}

The survey had revealed that this group of teachers and students were not highly confident computer users. It was therefore considered essential to design a working environment that was easy to learn and use, as well as having the required functionality. Since this was to be a system to support collaborative work, the chosen research methods originated in the Computer Supported Collaborative Work (CSCW) domain (Grudin, 1991, 1994a). The importance of considering human factors led to the adoption of user-centred methods from the Participatory Design movement - Carmel et al (1993) give an indication of the range of such methods. This meant that, instead of developing a system and testing it later with end users, the users were partners in the development from the beginning. Hémard and Cushion (2001) and Hinostroza and Mellar (2001) have shown that such an approach can be useful in developing learning materials and systems. The teachers and learning technologists collaborated on both language learning materials and on design of the working environment.

\section{- 2.4 The prototype virtual department}

The needs analysis had established that the virtual department would have to provide staffroom interaction for the teachers, and a space in which they could create, test and exchange learning materials. Students needed to communicate with one another and with teachers, and they needed language learning tasks that would enhance their classroom work.

A prototyping approach was used in order to refine requirements and to improve usability, both established uses of the method (Dix et al., 1993). A prototype can also be a useful communication tool: it can help resolve

3 . This goes somewhat counter to a traditional difficulty in computer-aided language learning (CALL): motivating teachers to produce their own learning materials (Hémard and Cushion, 2001). 
misunderstandings between users and developers (Gordon \& Bieman, 1995) ${ }^{4}$ and is "a valid means of transferring knowledge between developers and users" (Baumer et al., 1996). This was the second reason for choosing the method.

Because a VLE tool was used to create the prototype, it was possible to create the first version of the virtual department very early in the project and therefore to involve teachers in its design and development from the start. There were three main cycles of development and evaluation over the two years of the project.

\section{- 3. Using WebCT to implement the virtual department}

As already stated, the virtual department for Danish was based on the framework provided by a web-based learning environment, Web Course Tools (WebCT). This was available at UCL and is widely used in higher education, important because institutional support would be needed if the virtual department were to be sustainable in the longer term. WebCT provided a ready-made structure and tools for course delivery which could potentially be adapted to create a virtual department. It includes:

- self-contained 'course' structure made available via the web, accessible by user's name and password

- $\quad$ organised spaces to post materials and resources

- communication tools: discussion, e-mail and chat facilities

- student homepages: areas for students to write their own web pages, viewable by other students registered to the course

- student management tools: to assign students to groups for particular tasks or assignments

- user tracking tools: teachers can view student activity in terms of tasks accessed and length of time spent in the course environment

- assessment tools: facilities to design quizzes which can be scored and assessed automatically.

WebCT is designed to create courses and is therefore primarily an environment for students. It is possible to delimit access to certain areas, so that teachers or course designers can discuss issues or test resources without making them available to students. However, in this case it was decided to treat the teachers' and students' working areas as entirely separate 'courses'. This enabled teachers to have the full range of facilities (including communciation tools) that were available to students taking a course.

The teachers' area of the virtual department was established first, with the student area being set up once teachers had developed resources and gained some experience of the facilities available in WebCT. There were several reasons for this decision. First, the prototype course provided a 'test area'. As the teachers had little previous experience of designing or publishing webpages or other materials for delivery over the web, the initial

4 . The usefulness of prototyping does depend on the conditions under which the prototype is evaluated; it is essential that " evaluation conditions are similar to those anticipated for the actual operation." Dix et al (1993). In this case, the prototype was evaluated in its real context. 
stages of the project involved their learning to produce their own pages, and to make them 'live'. The test area provided a safe space, without any students registered to that course, in which they could publish, edit and delete pilot pages. In using this area without the pressure of producing 'polished' resources, the teachers could assess how best the environment could be used for their coursework. Second, the test space allowed the team to trial WebCT's communication tools: a discussion board was established, and teachers were encouraged to post to this as they encountered particular problems in their work. Separate discussion 'threads' were initiated, some for technical concerns, others for pedagogical ones, with the intention that solutions or advice could be shared by all members of the team. In using this communication facility, the teachers could begin to develop an awareness of online collaboration and how it might work with their groups of students.

In early 2001, the virtual department was introduced to students. This, as stated, was a second WebCT 'course', functioning solely for the delivery of completed materials and tasks to the students. The homepage is shown at Figure 1. It was believed that online collaboration between learners would be more effective where they had met face-to-face in the first instance. This, coupled with the idea that the virtual department should encourage social interaction amongst teachers and students, led to an important decision. Students and tutors would be brought together in London for one day, in order to learn to use the virtual department and to meet each other and get to know the people to whom they would be talking online. After this 'Student Day' the regular use of the virtual department by students began.

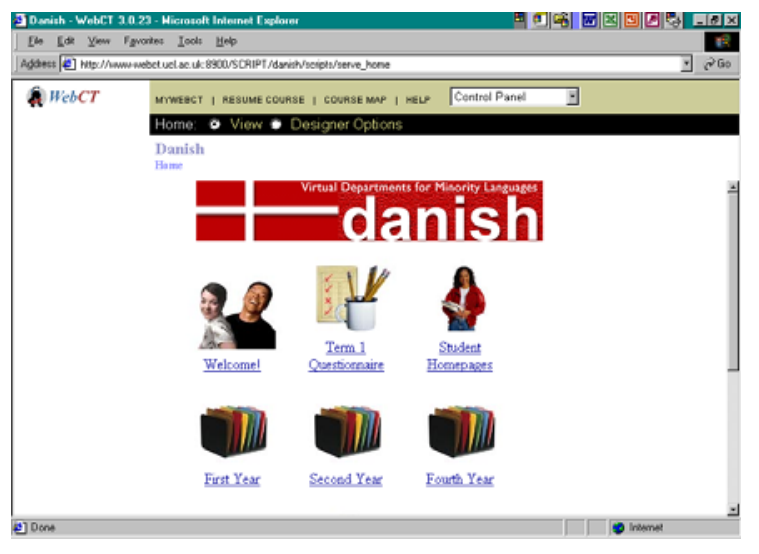

Figure 1: the Virtual Department (Students)

To summarise, then, the framework for the department is based on that provided by WebCT, but was initially based on two separate spaces or WebCT courses:

- $\quad$ a test and discussion area for use by the teachers in their initial exploratory work on developing resources for the web and for WebCT

- $\quad$ a second 'live' area, accessible to students and containing completed self-contained tasks, including collaborative tasks.

The next section will discuss the development of the content of the virtual department, and the variety of tools used by the teachers in creating tasks in accordance with their pedagogical aims. 


\section{- 4. Creating content for the virtual department}

\section{-4.1 Shared pedagogical goals}

With a framework in place that linked their departments and their students, the teachers also had a shared area in which to build a bank of materials and resources. They worked at different institutions and had different backgrounds and hence the first issue to be addressed was not technological. In order to produce resources that they could share, they felt it was important firstly to share their approaches in terms of preferred language learning methodologies, and to agree pedagogical criteria for the new resources. They referred to constructivist theory, which identifies social context, collaboration and problem-solving as important factors in enhancing students’ learning (Tam, 2000). Constructivist principles can be supported very well by the kinds of tools available in online learning environments such as WebCT. This process of negotiation was as important as learning to use the technology. The reflection on methodologies resulted in the following criteria for the materials being agreed (Roed et al, 2001). They should be:

- $\quad$ task-based: the materials would be organised in terms of carefully structured tasks based on the kinds of tasks students might have to complete in everyday life, and drawing on internet resources that native speakers in Denmark might use

- learner-centred: the tasks would require judgement and reflection on the part of the learner, rather than a 'Yes/No' answer

- communicative: audio and video resources would be produced, which could be accessed outside class time and therefore support development of spoken language outside class, while encouraging discussion of the materials in class

- $\quad$ authentic: the materials would exploit the range of authentic material available to teachers on the web as a whole, encouraging greater awareness of Danish culture and exposure to a greater variety of language.

These criteria also took account of ideas for communicative and integrative CALL supported by the Internet (Warschauer, 1996; Littlemore, 2001).

The virtual department provided the teachers with a central point in which to store the tasks they designed, and this quickly grew to accommodate the range of material they began to produce. The focus of this paper is on how well the technology supported what the teachers were trying to do. It is therefore important to state here what their aims were. Examples of tasks created by the teachers are at http://www.ucl.ac.uk/epd/herdu/vdml/. For a more detailed discussion of pedagogical aspects than is possible here, see Roed (2003) or Kristensen \& Rybner (2002).

\section{- 4.2 Tools for authoring web-based activities}

Choice of authoring tool was influenced by the need to create a lasting change in working practices, in small departments that were not generously funded and were unlikely to have their own technical support staff. The team therefore sought to use tools that were already available and supported in the three institutions and/or were freely available. They must also be relatively easy to learn and use. Even so, for teachers with no previous 
experience of web authoring and limited experience of other computer applications, learning to use this set of tools, together with WebCT, was a significant undertaking.

An important first step was the production of basic webpages in HTML. For this, a range of tools was used: Netscape Composer was used to write web pages which could be produced quite quickly and required little knowledge of HTML on the part of the teachers. Later, the institutions introduced Dreamweaver and this was adopted by the teachers. Basic graphics were produced and edited using Paint in Windows, and free graphics conversion packages downloaded and shared via WebCT. Existing audio resources the teachers had made (for instance, when on holiday in Denmark) were digitised using RealProducer (from RealMedia, http://www.real.com/) which could be downloaded freely.

One package which encouraged prolific generation of content for the site early in the development process was Hot Potatoes (from Half Baked Software, http://www.halfbakedsoftware.com/). This is a set of tools enabling the author to produce multiple-choice quizzes (Figure 2), crosswords, cloze tests, matching exercises and sentence ordering exercises ${ }^{5}$. This has several advantages which are worth highlighting here. First, the package was designed from a language teaching perspective, and it therefore includes tools whose usefulness was obvious to the teachers in that they mirrored the kinds of tasks they had produced on paper in the past. The packages use Javascript in tandem with HTML coding, but the ability to write this code is not required in order for the teacher to produce a web page with the task embedded in it. A supporting text with links to other resources can also be included alongside the exercise. The tasks produced by Hot Potatoes can be scored and timed if required: this allowed the teachers to create interactive elements which otherwise would have been difficult for them to encode in their webpages. Although the teachers were introduced to the quiz tools provided in WebCT, they used Hot Potatoes in preference, probably due to issues of usability as well as the fact that WebCT was not designed specifically to support language teaching and learning.

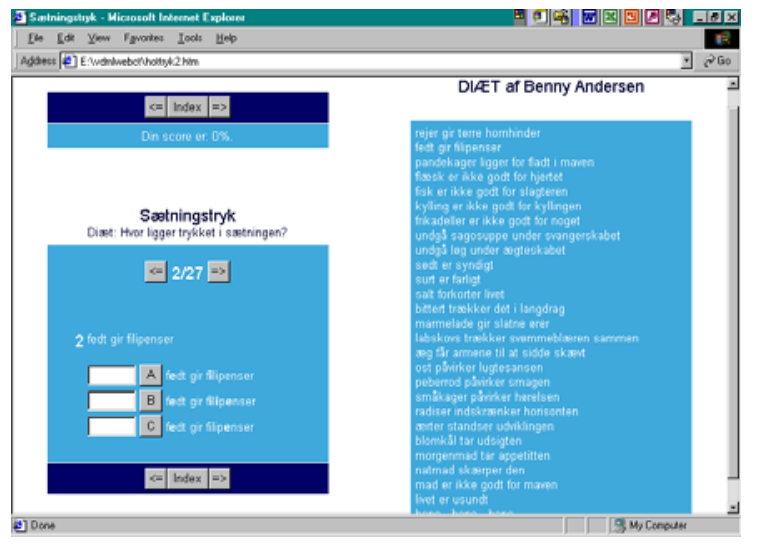

Figure 2: Example Hot Potatoes multiple-choice exercise

5. The package is available to download without charge to the user, on condition that the materials created are made freely available to others via the Internet. 


\section{- 4.3 Issues arising from task creation}

An interesting outcome of the development of content by the teachers early in the project was their increased awareness of the potential of the web to support a range of different exercises and tasks. Once they had passed the initial stages of publishing web pages and designing basic tasks , they began to plan resources that were technically quite complex and would call on a range of multimedia. This is worthy of discussion since it is unclear whether their growing interest was a consequence of the range of Internet-based Danish material that had become available to them for inclusion in tasks, or their increased awareness of the power of the online tools to produce new kinds of tasks for their students. This is a recurring issue in CALL, where web-based resources and tools have given rise to debate about whether the medium should be explored for its potential, or should be used solely to resolve a particular problem (Vogel, 2001). In this case, it seems to have been important to allow the teachers to explore the possibilities of the technology, since the single over-arching problem in their work was the shortage of teaching materials available to them.

As teachers' awareness of the potential of the web grew, it also became important for the technical members of the team to address how teachers could best be supported in producing their tasks. More complex tasks might call on sophisticated software which would not be available freely to them. Such tasks might also prove difficult to deliver over the web because of the multimedia used. One example of this process of negotiation and support arose with a task planned by two of the teachers which was to support students in learning phonetics and practising spoken Danish. The teachers planned a set of webpages, one each for pairs of vowel sounds in Danish. The pages would be divided into two sections, each containing a window to play a video clip of someone saying each sound, and a sample of words that included the sound. This would be supported by audio clips further down in the page for the individual words, and the phonetic characters for each would also be displayed. (A page from the exercise is included at Figure 3.)

This was an ambitious task: it required the production and editing of the audio and video clips, and their digitisation into formats that would be small enough to be delivered over the web as component parts of one page, but retaining sufficient audio/video quality to meet the objectives of the exercise. Filming the video clips was in itself a challenge since it required one of the teachers to act as the face on screen, yet all were geographically distant from one another. This was eventually done by incorporating the filming into a project meeting when all the teachers were present - a digital camcorder was available to the team and one teacher used this to film another reading the script. This film acted as a basic 'pilot' version of the clips to help with development of the pages, with a higher quality version being recorded professionally later on. Editing this film required specialist help and software which was provided by media production staff at UCL, and therefore this process of learning how to digitise and compress the video files could not be shared with the teachers designing the exercise.

Embedding the clips added a further complication, partly because of the multimedia 'plug-ins' required for students to play them, and because different university networks used different plug-ins for streaming media. The more straightforward text-based sections of the task brought another hurdle: the correct display of phonetic 
characters and special characters for Danish. These at first did not display in the same way on different computers, and in some cases WebCT did not display them at all. A series of steps to support the installation and testing of the fonts needed for these characters had to be developed for the teachers and team as a whole.

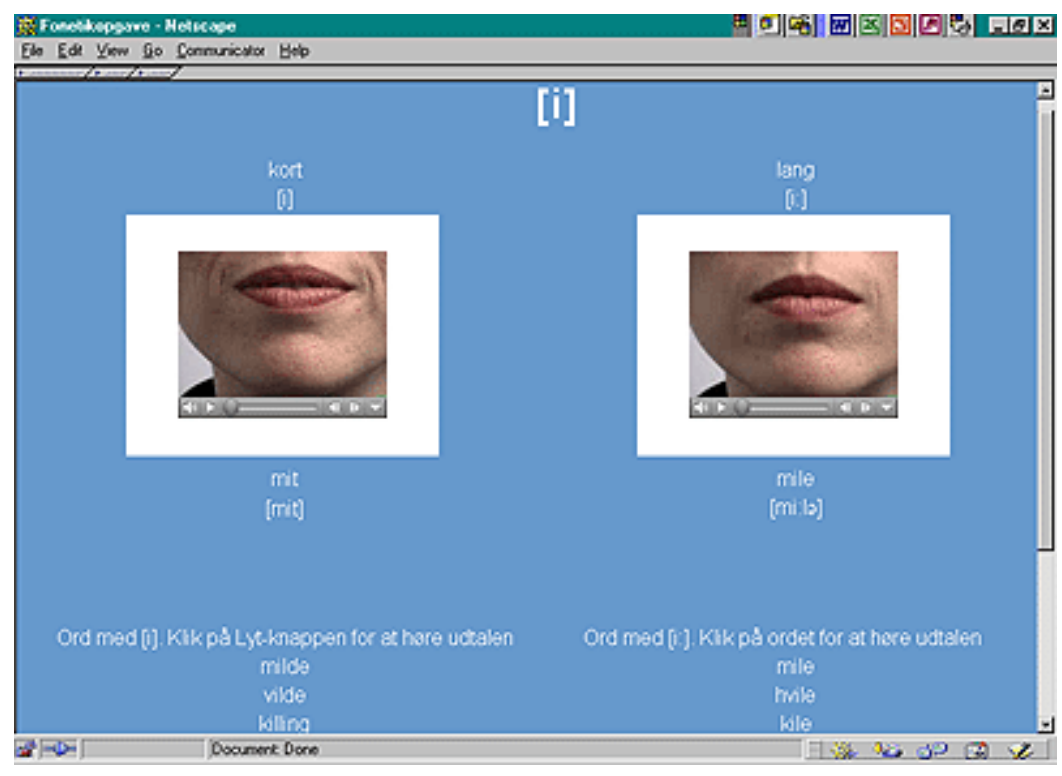

Figure 3: sample from the pronunciation/phonetics exercise

Thus, the realisation of this task by teachers and learning technologists presented a range of difficulties and resulted in processes of 'trading off' between content and the tools available to deliver that content. The original idea for the exercise was greeted enthusiastically by all the teachers on the team, and thought to be something that would be very suitable for self-access use by students, as well as exploiting the web and multimedia. There was no similar resource currently available to which they could direct students. However, the nature of the task meant that they could no longer rely on the freely available shared tools they had previously used. Costly equipment and software was necessary to produce the content they wished to provide to the students. They also had to consider in more depth the issues arising from delivering this kind of material using the web: previously they had benefited from the ability to produce webpages and interactive tasks quickly without any knowledge of the coding involved. The complex range of steps that needed to be completed before this task could be made available meant that they had to become familiar with a range of tools, and issues in using those tools, as well as overcoming a number of frustrations in the process as a whole.

\section{- 5. Evaluation of student activity in the Virtual Department}

\section{- 5.1 Overview of student evaluation}

Students began working in the virtual department in April, 2001. Evaluation is based on their use of it between then and the end of the VDML project, in Sepember 2002. Since the virtual department was developed as an 
ongoing resource, the emphasis was on formative evaluation, which would feed into continued development. Evaluation also considered how far the virtual department had met the needs of the students, as identified by the needs analysis.

A range of evaluative measures (see Table 1) was used in order to gather feedback from students and to establish when and how they used the virtual department, their reactions to the tasks and exercises produced, and their attitudes to learning online and collaboratively with students from other institutions.

\begin{tabular}{|l|l|l|}
\hline Activity & Evaluation questions & Methods \\
\hline $\begin{array}{l}\text { Student Day 1 - } \\
\text { Induction }\end{array}$ & $\begin{array}{l}\text { Can students use the materials and the } \\
\text { system without further support? }\end{array}$ & $\begin{array}{l}\text { On-line questionnaire; } \\
\text { Analysis of group discussion } \\
\text { involving teachers and students. }\end{array}$ \\
\hline $\begin{array}{l}\text { Student Day 2 - } \\
\text { Evaluation }\end{array}$ & $\begin{array}{l}\text { How far is the virtual department } \\
\text { meeting student needs? } \\
\text { What further improvements are needed? }\end{array}$ & $\begin{array}{l}\text { Student focus groups; } \\
\text { involving teachers and students. }\end{array}$ \\
\hline Analysis of Log Files & $\begin{array}{l}\text { Are students using the virtual } \\
\text { department? } \\
\text { How are they using the virtual } \\
\text { department? }\end{array}$ & $\begin{array}{l}\text { Analysis of WebCT student } \\
\text { tracking data }\end{array}$ \\
\hline
\end{tabular}

Table 1. Summary of student evaluation activities

These evaluation activities are discussed in the following sections.

\section{- $\quad$ 5.1.1 Student Day 1 - Induction}

The 'Student Day' provided an ideal opportunity to gather evaluative data from the students as they used the virtual department for the first time. Students undertook four tasks, selected both to cover varied learning objectives and to represent the range of technology they would encounter when using the virtual department site. This included use of WebCT's communication tools, use of authentic Danish web sites, audio and video based tasks and a selection of interactive tasks developed using Hot Potatoes. Further information about the tasks can be found at http://www.ucl.ac.uk/epd/herdu/vdml/activities/studentdays/tasks.html .

Students submitted a short online evaluation of each task as they completed it, a mixture of multiple choice and open ended questions, as in the examples in Table 2. A face-to-face discussion with the whole group was recorded at the end of the day's activities. Teachers were also able to observe the students as they worked on the tasks. 


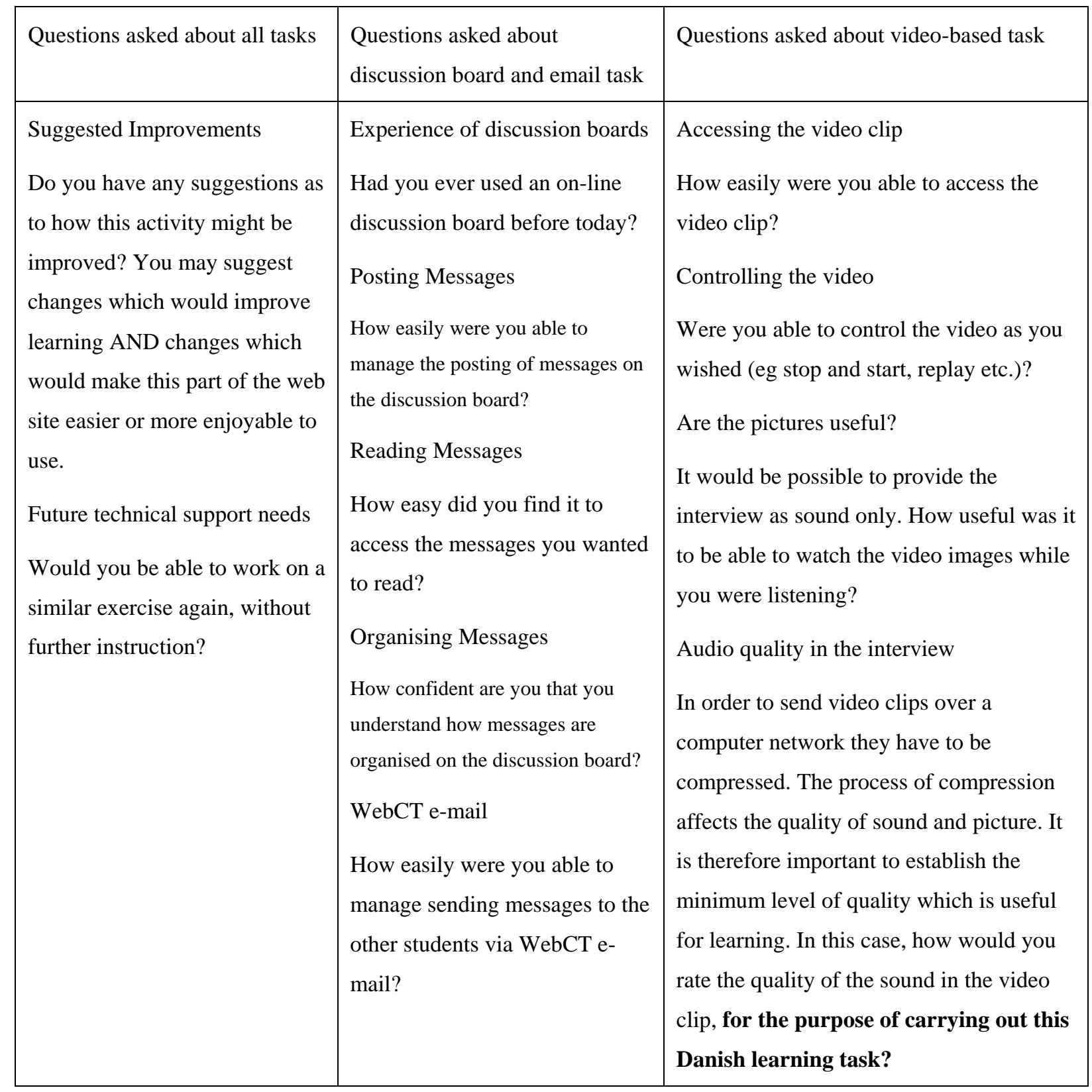

Table 2 Examples of online evaluation questions, Student Day 1

The online evaluation forms indicated a high level of enthusiasm for the new tasks, especially those incorporating sound and video. They also showed that none of the students had experienced significant difficulty using the WebCT student area. A task based on the use of the discussion board was received positively, with suggestions that e-mail and chat should also be incorporated into the exercises. This seemed to suggest that students were keen to work on tasks which called on their collaboration with others, and the use of online communicative tools. Teachers reported that observation had revealed the need to break some tasks into smaller units and had shown that instructions needed to be more explicit in certain cases, particularly when students were asked to navigate through web sites in Denmark.

The discussion at the end of the session brought out other aspects of the tasks and the ways in which the students had used them. They valued the individual control that on-line learning can provide; being able to replay video 
individually meant that they were able to work on particular questions until they had found the answers. They referred to having to 'work things out' from the video clips in order to complete a task. They enjoyed the independence of accessing the resources themselves, and completing tasks in their own time, but also reiterated their enjoyment of the communicative tasks. One learner commented that writing in Danish was easier when it was done for the discussion board task - it was non-formal but provided a chance to practise, as well as giving her 'something to hide behind' rather than exposing her to the rest of the group in a face-to-face situation. The impact of new technologies on communication has, of course, been extensively discussed. Shetzer and Warschauer (2000) refer to the Internet as 'becoming one of the primary media of literacy and communication practices in the current era'. Student response suggested that the virtual department could provide a context in which to explore new communicative opportunities. Students also raised questions about learners' confidence, and the support learners can gain from each other. They felt it might be easier to call on each other for help in some cases than to call on the teachers. This option had not previously been available to them, or had been severely limited, by the size of their year groups.

\section{- $\quad$ 5.1.2 Student Day 2 - Evaluation}

A second Student Day was held in February 2002 and attended by some of the students who had been first year undergraduates at the time of the first event, as well as the new first year cohorts. This time, evaluation was the main purpose of the day, and was done in the context of the students' use of the virtual department over the whole of the academic year, rather than being based on any tasks they completed during the day. Focus groups were arranged with first year and second year students from each of the universities.

Perhaps the most important finding was that technology had not proved to be a barrier to the students: in general, they had been able to access the resources (including multimedia resources) and to engage with the tasks. Some more general technical issues had to be addressed, however, whether or not Danish characters could be typed onto the screen, for instance, or whether soundcards were available in certain networked computer rooms. The students felt that the resources available to them could support them in ways we might associate with conventional CALL: grammar, developing vocabulary, revising and as a reference point. However, they also expressed strong wishes to have more task-based material, particularly that involving authentic Internet-based material from Denmark. In addition, they stressed that the department could and should be used more for communication between students across the universities (see also next section). One student found the site very useful for listening to Danish but did not like reading text from a monitor. Students were divided as to whether the materials should be organised thematically (as they are currently) or by grammar topics - but in general they wanted more material, and said that they would access it over the summer vacation.

\section{- $\quad$ 5.1.3 WebCT Student Tracking}

WebCT provides information about student activity in the virtual learning environment. This data was studied in conjunction with the qualitative data already described. However, interpretation has been cautious. The behaviour of WebCT student tracking depends to an extent on how learning materials have been organised within WebCT. Because of this, information about the details of student activity is not consistent for all students 
in the earlier part of the project ; therefore only data at the top level (number of accesses) has been included in the evaluation.

72 students worked in the virtual department between April 2001 and October 2002, with numbers from the three universities being 32, 20, 20. Their courses varied in length, and some were only able to use the resource for a short period of time. The work of the two groups who had access for a complete academic year is reported here: Group A consists of 10 students who used the virtual department for a year beginning in April 2001. Group B consists of the 7 students who registered in October or November 2001 and continued to use the resource until October 2002. Table 3 shows the number of times these students accessed resources in the virtual department. This shows an apparent increase over time in the level of use. It is suggested that this is partly due to an increase in the number of available tasks; teachers built up a bank of materials which they all could use. They had also had time to develop ways to integrate the materials into their courses, which may have led to increased use of the student area.

\begin{tabular}{l|l|l|l||} 
Group & Mean number of accesses & Range & Values \\
\hline A & 152 & $90-450$ & $90,93,100,104,128,130,136,139,147,450$ \\
\hline B & 309 & $107-522$ & $107,276,369,230,398,267,522$ \\
\hline
\end{tabular}

Table 3 : Student access to virtual department - Groups A and B

\section{- $\quad$ 5.1.4 Reflection on student evaluation}

Overall, evaluation conducted with students suggested that their response to sharing tasks and communicating with other students via the virtual department was very positive, although, perhaps paralleling the experience of the teachers, as they became more aware of its potential they began to demand more and new materials. They made a number of suggestions as to the kinds of resources they would like to see included in the future, and how they would use these. There is an issue here in terms of managing student expectations - and the extent to which teachers can juggle their development work for a 'virtual' department amongst all their responsibilities in their 'real' departments. However, it is interesting to note that already students had a wider view of how the web could be used to support their learning than might have been reflected by the initial survey data. It is not only a question of computers reinforcing points of grammar or vocabulary, but it can be useful in aural and spoken communication, as well as collaborative tasks.

\section{- 5.2 Evaluating teacher activity: issues in using WebCT}

The initial research question was whether the VLE, WebCT, could support the students' and teachers' needs, in terms of both communication opportunities and availability of learning materials. From student evaluation it seemed that the virtual department did offer them the communication and working opportunities they needed. The teachers' activity in the virtual department over its first year was also evaluated. 
At the mid-point of the project in 2001, the teachers were surveyed and the team found that they remained enthusiastic about the potential of the technologies to help them achieve their objectives in terms of providing new resources for their students. They were pleased with the response of students to the new resources, and as a result of the first Student Day they had a greater understanding of the kinds of activities the students would benefit from doing. They were keen to develop further their own technical skills, but they also had a far greater awareness of the technical problems they had encountered or were likely to encounter in the future. This enabled them to identify specific support and training needs which the project could then address.

However, observation of activity and the teachers' own reports made it clear that their working area was still causing them some difficulties, and neither the communication area nor the resource sharing area was being used fully. To help the team understand the reasons for these difficulties, a usability evaluation of WebCT (Watson, 2001) was carried out. This identified problems in using the file management area as significant obstacles for the teachers. In order to explore the problems, an alternative working area for the teachers was developed, with the aim of providing them with an enhanced resource bank, and improving online communication.

\section{- $\quad$ 5.2.1 Shared resource bank}

The launch of the 'live' area for students to access finished materials marked a change in the way teachers used WebCT for prototyping and testing materials. One reason for this was the emergence of usability difficulties in WebCT: the file management area provided by WebCT was not found to be user-friendly by the teachers, and they tended towards using it only to upload finished materials rather than drawing on it for existing resources and to produce new ones. A second reason why it proved unsatisfactory was that it is not searchable. It became clear that it would not be possible to use this structure in the longer term: we would need a system whereby teachers could perform searches using different categories to find resources that could be used or re-used to produce a task.

\section{- $\quad$ 5.2.2 Shared communication}

The prototype area had included the range of communication tools available to teachers in WebCT: discussions, e-mail and chat. However, in practice, the teachers tended to rely on the existing project mailing list (a standard e-mail list, accessed via their conventional e-mail packages). This was usually quicker for them, both in contacting one another and asking for technical support. They used e-mail on a daily basis but might not always refer to the test area each day. However, the disadvantage with relying solely on e-mail is the loss of a resource in the form of archived messages and previous answers to technical or other problems. Although an archive of email messages and responses was still maintained by the technical team, this was not readily accessible to the teachers. Therefore, although they were sharing communication, and collaborating extensively in the design and production of their resources, they were not using the tool which would support this process most effectively in the long term. 
- $\quad$ 5.2.3 Resolving these issues: virtual staff room and virtual desktop?

The WebCT-based teachers' area had enabled the team to refine the requirements and had highlighted problems. The development of the alternative working area for teachers was a key focus for the remainder of this project: a new prototype area was produced with the aim of providing them with both a 'virtual desktop', by which we mean searchable sets of resources presented in a recognisable way, mirroring the design of file management in Windows operating systems; and a 'virtual staff room' - a more effective threaded discussion board which provided a viable alternative to the e-mail list. The intention was that they would make greater use of this if they were making greater use of the shared resource area. In this way, the somewhat disparate strands of the original Virtual Department - e-mail, WebCT test area and WebCT 'live' student area - could be brought together.

However, this exercise revealed how difficult it can be to make a technological solution acceptable to the users and how other factors, besides the functionality of the technology, are strongly influential. The teachers reported that the new working area offered what they required. They did not, however, use it regularly. Despite their problems with WebCT, they continued to use this tool. It is suggested that this is partly because the adoption of Dreamweaver by the institutions meant they now had a powerful web authoring tool that could be linked with WebCT. It is likely that they had also become accustomed to WebCT after a year of use, and had found their own ways of working round the aspects they found most problematic. As stated earlier, however, in doing this, they lost the potential to keep records of their thoughts and discussions as well as the outcomes.

\section{- 6. Conclusions: Sharing Systems and Sharing Language}

The need for collaboration having been identified, the three Danish departments were linked successfully in the web-based virtual department. This has been of immediate benefit to staff, who say they 'now have colleagues'. From the students' point of view, they now have fellow learners and sources of support other than their teachers. These benefits are likely to continue ; the use of a VLE which was already supported in one of the institutions means that support services will continue to be available to the teachers and students.

The delivery of material to students through the virtual learning environment has enabled them to communicate and collaborate on work, as well as developing or consolidating their language learning through tasks including multimedia and interactive features. However, the benefits for students do depend on their teachers being able to provide enough learning materials; this research has shown that this was a significant effort for the teachers and a potential problem area. Having said this, the teachers involved in the research stated that being able to share resources, and use materials created by their colleagues, compensated for the increased initial workload.

The use of the virtual learning environment, as a test area for new resources by the teachers, has shown that these systems can be used by teachers as well as students. Teachers and students working in a virtual environment need a similar set of tools and these technologies have created frameworks for the sharing of pedagogical discussion. There were reservations about the design of this particular tool but the development of the second 'shared area' incorporating discussion board and searchable resource banks, showed how the use and re-use of teaching materials might be encouraged, with potential benefits in terms of both the sharing of work load and the exchange of good practice between teachers. 


\section{- 7. Discussion:}

These findings potentially provide us with a model which could be transferred to other minority or less widely taught and used languages. This is not only in terms of the types of technology which might be used to make other virtual departments, but also in terms of the consideration of pedagogical and cultural issues which have arisen. Teachers of other languages might be encouraged by the practical benefits of collaboration: the Danish teachers involved in this project found that their investment of time in developing new resources was recouped by the ability to share and re-use their colleagues' resources. The project may provide a model for CALL more generally, including as it does the approaches outlined by Hémard and Cushion (2001): involving learners and teachers in the design process, obtaining qualitative and quantitative data on the system in use, and encouraging staff to produce their own authentic materials.

The findings may also lead to reflection on the introduction of technology-based changes to the way that language teachers work. Although it is clear that ease of use and provision of essential functions and facilities will affect the use and acceptability of a new software tool, teachers will work through difficulties, as these did, and may be influenced by factors such as the links with other tools as, in this case, Dreamweaver influenced the way that WebCT was used.

It is important for us to continue to reflect on the nature of the tools provided by the virtual department, and how these affect the choices teachers make in providing their authentic resources in Danish. A consideration of these processes might examine how the culture of the virtual department differs from that of a 'real' department, and in so doing enable us to learn more about our existing practices in our disciplines. What makes the department what it is, and do the tools provided by new technologies lead to new working practices? The three departments concerned in this research are keen to continue working in the virtual Danish department. This will provide opportunities to explore these processes and practices further and to gain further insights into the ways in which a new language may be shared with learners. 


\section{- $\underline{\text { References }}$}

Baumer, D., Bischofberger, W.R., Lichter, H., Zullighoven, H. (1996): User Interface Prototyping - Concepts, Tools and Experience. Proceedings of ICSE (18 ${ }^{\text {th }}$. International conference on Software Engineering) 1996, Los Alamitos, CA: IEEE Computer Society Press, [pp 532 - 541].

Carmel, E., Whittaker, R.D., George, J.F. (1993): PD and Joint Application Design: a Transatlantic Comparison. Communications of the ACM 36/6, special issue on Participatory Design, New York, NY: ACM Press, [pp 40 48].

Dix, A., Finlay, J., Abowd, G., Beale, R. (1993) Human-Computer Interaction. UK: Prentice-Hall

Fitzpatrick, T. (ed) (2000) European Language Learning Materials Survey. European Commission http://europa.eu.int/comm/education/languages/download/survey.html (last accessed: 25 February 2002)

Gordon, S.V., Bieman, J.M. (1995) Rapid Prototyping: The Lessons Learned. IEEE Software, January 1995

Grudin, J. (1991) : CSCW : The convergence of Two Development Contexts. Communications of the ACM December 1991, 34 (12), New York NY : ACM Press, [pp91-97].

Grudin, J. (1994a) : Computer Supported Cooperative Work : Its History and Participation. IEEE Computer, 27 (5), [pp19-26]

Grudin, J. (1994b) : Groupware and Social Dynamics : Eight Challenges for Developers. Communications of the ACM, 37 (1), New York, NY : ACM Press, [pp92-105]

Hémard, D. \& Cushion, S. (2001) Evaluation of a web-based language learning environment: the importance of a user-centred design approach for CALL. ReCALL 13 (1) (15-31)

Hinostroza, J.E., Mellar, H. (2001): Pedagogy Embedded in Educational Software Design: Report of a Case Study. Computers \& Education, 37, [pp 27-40]

HotPotatoes from Half-Baked Software: http://www.halfbakedsoftware.com/. (last accessed: 25 February 2002) Joint Information Systems Committee (JISC) http://www.jisc.ac.uk/. (last accessed: 29 May 2002)

King, J.T. (2001) Reports on the VDML Survey http://www.ucl.ac.uk/epd/herdu/vdml/survey/index.htm (last accessed 29 May 2002)

Kristensen, A. \& Rybner, L. (2002) Dansk som fremmed - og "minoritetsprog”. Forskning i Nordisk Sprog som Andet- og Fremmedsprog, pp. 278-294. Reykjavik: University of Iceland Press

Littlemore, J. (2001) Learner autonomy, self-instruction and new technologies in language learning: Current theory and practice in higher education in Europe. In A. Chambers \& G. Davies (eds) ICT and Language Learning: A European Perspective. Lisse: Swets \& Zeitlinger.

Lunt, P.\& Livingstone, S. (1996) Rethinking the Focus Group in Media and Communications Research. Journal of Communication 46(2) (79-98)

RealProducer, from Real Media: $\underline{\text { http://www.real.com/(last accessed } 18 \text { February 2002) }}$ 
Roed, J., McAvinia, C. \& Hughes, J. (2001) Learning to work in a Virtual Department in CALL: The Challenge of Change, Proceedings of the CALL Conference, University of Exeter, 1-3 September 2001.

Roed, J. (2003) : Language Learner Behaviour in a Virtual Environment. Computer Assisted Language Learning Vol. 16, No.2-3, [pp. 155-172]

Tam, M. (2000) Constructivism, Instructional Design, and Technology: Implications for Transforming Distance Learning. Educational Technology and Society 3(2) http://ifets.ieee.org/periodical/vol_2_2000/tam.html (last accessed 6 February 2002)

Vogel, T. (2001) Learning out of control: Some thoughts on the World Wide Web in learning and teaching foreign languages. In A. Chambers \& G. Davies (eds) ICT and Language Learning: A European Perspective. Lisse: Swets \& Zeitlinger.

Warschauer, M. (1996) Computer-assisted language learning: An introduction. In S. Fotos (ed.), Multimedia Language Teaching. Tokyo: Logos International

Shetzer, H., \& Warschauer, M (2000). An electronic literacy approach to network-based language teaching. In M. Warschauer \& R. Kern (eds.), Network based language teaching: Concepts and practice. New York: Cambridge University Press.

Watson, A. (2001) Usability Report on WebCT for the VDML Project, at http://www.ucl.ac.uk/epd/herdu/vdml/activities/evaluation/index.htm (last accessed: 29 May 2002)

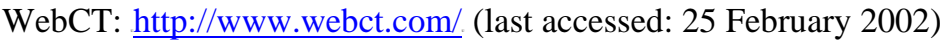

